\title{
Photocatalytic Decolourization and Degradation of C. I. Basic Blue 41 Using $\mathrm{TiO}_{2}$ Nanoparticles
}

\author{
Abdulraheem Giwa ${ }^{*}$, Peter Obinna Nkeonye, Kasali Ademola Bello, Kasali Ademola Kolawole
}

Department of Textile Science and Technology, Ahmadu Bello University, Zaria, Nigeria.

Email: *agiwa@abu.edu.ng

Received June $10^{\text {th }}, 2012$; revised July $11^{\text {th }}, 2012$; accepted August $12^{\text {th }}, 2012$

\begin{abstract}
The nanophotocatalytic process using semiconducting oxides with a nanostructure is one of the technologies used for the destructive oxidation of organic compounds such as dyes. The photocatalytic oxidation of a textile dye-C. I. Basic Blue 41 (BB41) in aqueous solution was assessed by UV ray irradiation in the presence of $\mathrm{TiO}_{2}$ nanoparticles. The effect of initial dye concentration, $\mathrm{pH}$ and $\mathrm{TiO}_{2}$ loading were investigated and the optimized conditions for maximum amount of degradation were determined. Analysis of the kinetics showed pseudo-first-order model. The mineralization of the dye was reported by measuring the initial and final chemical oxygen demand of the solution that was irradiated under optimized conditions.
\end{abstract}

Keywords: Nanophotocatalysis; Textile; Dye; Wastewater; $\mathrm{TiO}_{2}$; C. I. Basic Blue 41

\section{Introduction}

Synthetic dyes comprise an important part of industrial water effluents that are discharged by many manufacturing industries. The impact of these dyes on the environment is a major concern because of the potentially carcinogenic properties of the chemicals [1]. Also, some dyes can undergo anaerobic decolouration to form potential carcinogens [2]. The wastewater which is coloured in the presence of these dyes can block both sunlight penetration and oxygen dissolution that are essential for aquatic life. Consequently, there is a considerable need to treat these coloured effluents before discharging them into various water bodies. Various approaches on handling and decontaminating such effluents have been reported in the literature. Typical techniques include the classical methods such as adsorption [3,4], coagulation [5,6], ion flotation [7] and sedimentation [8]. All these techniques are versatile and useful, but they all end up in producing a secondary waste product that needs to be processed further. Another set of techniques that are relatively newer, more powerful, and very promising called Advanced Oxidation Processes (AOPs) has been developed and employed to treat dye-contaminated wastewater effluents [9].

The semiconductor $\mathrm{TiO}_{2}$ nanoparticles has been widely utilised as a photocatalyst for inducing a series of reducetive and oxidative reactions on its surface. This is solely

*Corresponding author. attributed to the distinct lone electron characteristic in its outer orbit. When photon energy (hv) of greater than or equal to the bandgap energy of $\mathrm{TiO}_{2}$ is illuminated onto its surface, usually $3.2 \mathrm{eV}$ (anatase) or $3.0 \mathrm{eV}$ (rutile), the lone electron will be photo-excited to the empty conduction band in femto seconds. The mechanism of the electron hole pair formation when the $\mathrm{TiO}_{2}$ particle is irradiated with adequate hv is depicted in Figure 1.

Photocatalysis using $\mathrm{TiO}_{2}$ as photo-catalyst degrade toxic organic compounds [10], reduce metal-ions [11], improve the biodegradability in cellulose effluents [12] and decolour a great variety of dyes in solution [13] or in

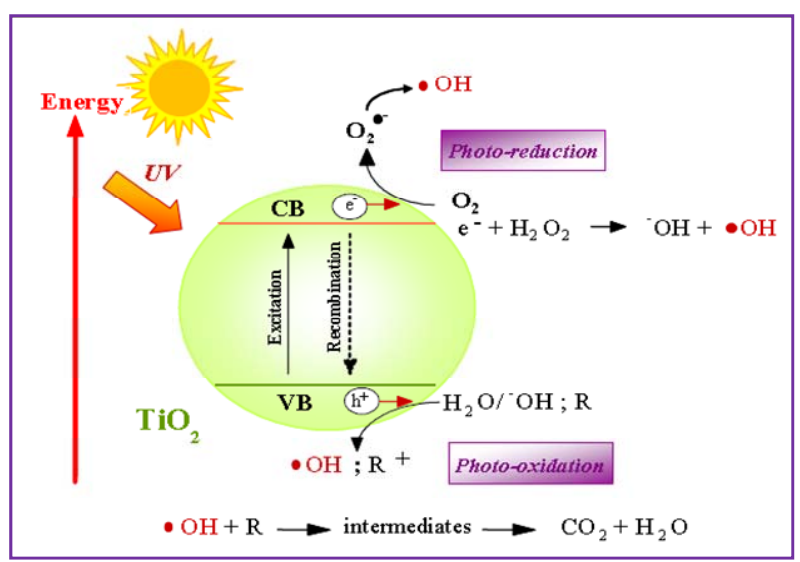

Figure 1. Schematic diagram of an irradiated $\mathrm{TiO}_{2}$ semiconductor particle with photo-chemical and photo-physical process. 
solid mixtures [14]. When titania suspensions are irradiated, electrons are excited from the valence to the conduction band, generating positive holes and electrons $[9,10]$ :

$$
\mathrm{TiO}_{2}+h v(<390 \mathrm{~nm}) \rightarrow \mathrm{TiO}_{2}\left(\mathrm{e}^{-}+\mathrm{h}^{+}\right)
$$

The energy band gap for $\mathrm{TiO}_{2}$ Degussa P-25, the most used photocatalyst, is around $3.2 \mathrm{eV}(390 \mathrm{~nm})$. Electrons and holes can recombine (Equation (2)) or react with other molecules, such as oxygen, generating reactive superoxide anions (Equation (3)).

$$
\begin{aligned}
& \mathrm{TiO}_{2}\left(\mathrm{e}^{-}+\mathrm{h}^{+}\right) \rightarrow \mathrm{TiO}_{2}+\text { heat } \\
& \mathrm{TiO}_{2}\left(\mathrm{e}^{-}\right)+\mathrm{O}_{2} \rightarrow \mathrm{TiO}_{2}+\mathrm{O}_{2}^{--}
\end{aligned}
$$

The positive holes can react with electron donors in the solution to produce hydroxyl radicals (Equations (4) and (5)) or would directly oxidise organic molecules (OM) at the semi-conductor surface (Equation (6)).

$$
\begin{aligned}
& \mathrm{TiO}_{2}\left(\mathrm{~h}^{+}\right)+\mathrm{H}_{2} \mathrm{O}_{(a d s)} \rightarrow \mathrm{TiO}_{2}+\mathrm{H}^{+}+\mathrm{OH}_{(a d s)}^{\cdot} \\
& \mathrm{TiO}_{2}\left(\mathrm{~h}^{+}\right)+\mathrm{OH}^{-} \rightarrow \mathrm{TiO}_{2}+\mathrm{OH}_{(a d s)}^{\cdot} \\
& \mathrm{TiO}_{2}\left(\mathrm{~h}^{+}\right)+\mathrm{OM} \rightarrow \\
& \text { degradation intermediates } \mathrm{TiO}_{2}+\mathrm{OM}^{\cdot+}
\end{aligned}
$$

The hydroxyl radicals generated in the process are strong oxidants and react quickly with the organic matter adsorbed on the catalyst (Equation (7)), forming oxidised intermediates, and if the treatment time is adequate, complete mineralization is achieved.

$$
\begin{aligned}
& \mathrm{OM}+\mathrm{HO}_{(a d s)}^{\cdot} \rightarrow \text { degradation intermediates } \\
& \rightarrow \mathrm{CO}_{2}+\mathrm{H}_{2} \mathrm{O}+\text { salts }
\end{aligned}
$$

The typical mechanism involving hydroxyl oxidative radical reactions go through the steps: electron transfer, hydrogen abstraction and addition to aromatic rings/ double bonds $[9,10]$.

In many cases the macromolecule is completely mineralized into water and carbon dioxide. The AOP technique has drawn considerable attention from various quarters of scientific community as it is easy to handle and produces significantly less residuals as compared to the classical approaches. Amongst the many techniques employed in the AOP approach are the UV photolytic technique $[15,16]$, Fenton process $[17,18]$, photo-Fenton process [19,20], ozonation process [21], sonolysis [22,23], photocatalytic approach [24,25], biodegradation [26,27] and the radiation induced degradation of dyes [28,29].

Various physico-chemical techniques are available for the elimination of dyes from wastewater and in particular photocatalysis is a more promising tool. Moreover, photocatalysis can be used to cause redox transformations and decompose a dye molecule. The use of photosensi- tive semiconductors such as $\mathrm{TiO}_{2}, \mathrm{ZnO}, \mathrm{Fe}_{2} \mathrm{O}_{3}$, $\mathrm{CdS}$, $\mathrm{ZnS}$ and $\mathrm{V}_{2} \mathrm{O}_{5}$ has been reported in the literature for their use in reducing colour of the dye solutions owing to their environmental-friendly benefits in the saving of resources such as water, energy, chemicals, and other cleaning materials [30,31]. Titanium dioxide $\left(\mathrm{TiO}_{2}\right)$ mediated based photodegradation has attracted extensive interest owing to its great advantages in the complete removal of organic pollutants from wastewater [32]. This is mainly because of its various merits, such as optical-electronic properties, low-cost, chemical stability, and non-toxicity [33]. The aim of the research, was to study the photocatalytic process using $\mathrm{TiO}_{2}$ nanoparticles in the form of slurry for the decolourization and mineralization of C. I. Basic Blue 41 (BB41).

\section{Materials and Methods}

BB41, commercially called Cationic Blue GRL (C. I. 11105 ) is a reactive dye bearing an azo group as chromophore, with a molecular weight of 482.57 and molecular formula $\mathrm{C}_{20} \mathrm{H}_{26} \mathrm{~N}_{4} \mathrm{O}_{6} \mathrm{~S}_{2}$ manufactured by Dongwu Dyestuff Co. Ltd. China was obtained from a retail outlet. Titanium dioxide (Degussa P25) was utilized as a photocatalyst. Its main physical data are as follow: average primary particle size around $21 \mathrm{~nm}$, purity 99.5\% and BET surface area $50 \pm 15 \mathrm{~m}^{2} / \mathrm{g}$. A UV-Vis Spectrophotometer, UV-1700 PharmaSpec, Shimadzu was used to determine the decolourization rate. The photocatalytic activities of the photocatalysts were performed in a 400 ml jacketed glass reactor fitted with a 9W 5" long Philips (PL-S 9W/10/2P Hg) bulb.

The slurry composed of dye solution and catalyst placed in the reactor was stirred magnetically. After photocatalytic treatment, samples were centrifuged (6000 rpm, $10 \mathrm{~min}$ ) and filtered through a millipore filter (0.45 $\mu \mathrm{m})$ membrane and analyzed for the concentration of the BB41 in the solution using computer software attached to UV-Vis Spectrophotometer. Photocatalytic degradation processes were performed using a $200 \mathrm{ml}$ solution containing a specified concentration of selected dye. Samples were withdrawn from sample points at certain time intervals and analyzed for decolourization and degradation. Decolourization of dye solutions was checked and controlled by measuring the maximum absorbance of dyes at different time intervals by UV-Vis Spectrophotometer. The maximum absorbance of BB41 in the visible region of UV-Vis spectrum was $608 \mathrm{~nm}$. COD tests were used to assay the mineralization of BB41.

\section{Results and Discussion}

\subsection{Decolourization Kinetics}

The variation of $-\ln \left(C / C_{0}\right)$ of $B B 41$ with irradiation 
time is shown in Figure 2. It can be observed that decreasing dye concentration is linearly related to the elapse of irradiation time. This means that the pseudofirst-order kinetics relative to dye is operative.

As the Langmuir-Hinshelwood (L-H) model is a surface-area dependent, the reaction rate is expected to increase with irradiation times since less organic substrate will remain after increased irradiation times with higher surface availability. A zero rate of degradation is associated with the total decomposition achieved. Numerous assumptions for the L-H saturation kinetics type exist and for the applicability in the rate of photo-mineralization, any of the four possible situations is valid:

1) Reactions take place between two adsorbed components of radicals and organics;

2) The reactions are between the radicals in water and adsorbed organics;

3) Reactions take place between the radical on the surface and organics in water;

4) Reaction occurs with both radical and organics in water.

Some researchers $[34,35]$ found that simpler zero or first-order kinetics is sufficient to model the photo-mineralization of organic compounds. This was, however only applicable for limited conditions where the solute concentration is inadequately low. In most kinetic studies, a plateau-type of kinetic profile is usually seen where the oxidation rate increases with irradiation time until the rate becomes zero [34]. The appearance of such kinetics regime usually fits the L-H scheme. According to the L$\mathrm{H}$ model (Equation (8)), the photocatalytic reaction rate $(r)$ is proportional to the fraction of surface coverage by the organic substrate $\left(\theta_{x}\right), k_{r}$ is the reaction rate constant, $C$ is the concentration of organic species and $K$ is the Langmuir adsorption constant:

$$
r=-\frac{\mathrm{d} C}{\mathrm{~d} t}=k_{r} \theta_{x}=\frac{k_{r} K C}{1+K C}
$$

The applicability of Equation (8) depends on several assumptions that include

1) The reaction system is in dynamic equilibrium;

2) The reaction is surface mediated;

3) The competition for the $\mathrm{TiO}_{2}$ active surface sites by

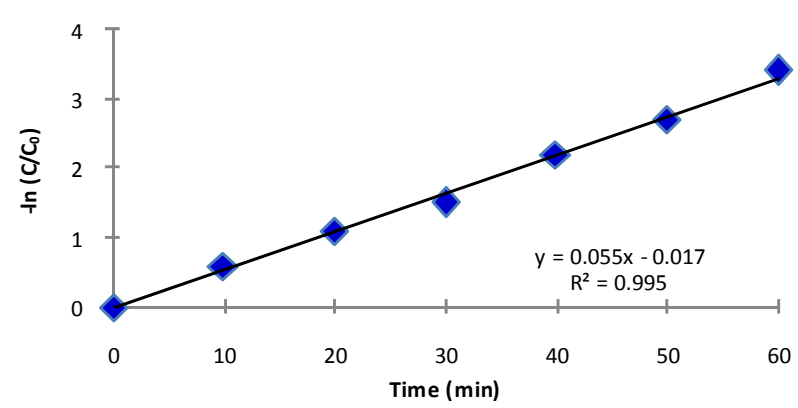

Figure 2. Pseudo-first-order decolourization rate of BB41. the intermediates and other reactive oxygen species is not limiting [35].

If these assumptions are valid, the reactor scheme only consists of adsorption surface sites, organic molecules and its intermediates, electron-hole pairs and the reactive oxygen species. The rate constant $\left(k_{r}\right)$ for most of the photocatalytic reaction in water is usually reported to be in the order of $10^{6}-10^{9}(\mathrm{Ms})^{-1}$ [36]. This $k_{r}$-value is the proportionality constant for the intrinsic reactivity of photo-activated surface with C. Others have also related the $k_{r}$ is proportional to the power law of effective radiant flux (i.e. $\phi_{e}^{n}$ ) during the photomineralization reaction [37]. The $K$-parameter is the dynamic Langmuir adsorption constant $\left(\mathrm{M}^{-1}\right)$ that represents the catalysts adsorption capacity. Equation (8) can be solved explicitly for " $t$ " using discrete change in $C$ from initial concentration to a reference point:

$$
\ln \left(\frac{C}{C_{0}}\right)+K\left(C-C_{0}\right)=-k_{r} K t
$$

The $K$-value can be obtained using a linearized form of Equation (8), where $1 / \mathrm{r}$ is plotted against $1 / C$ :

$$
\frac{1}{r_{0}}=\frac{1}{k_{r}}+\frac{1}{k_{r} K C_{0}}
$$

It was reported that the real $K$-value obtained from the linearized plot of $1 / r$ against $1 / C$ is significantly smaller [36]. This was explained by the differences in adsorption-desorption phenomena during dark and illuminated period. When the organics concentration is low (in $\mathrm{mM}$ ), an "apparent" first-order rate constant Equation (11) could be expressed where $k^{\prime}\left(\mathrm{min}^{-1}\right)=k_{r} K$ :

$$
r=-\frac{\mathrm{d} C}{\mathrm{~d} t}=k_{r} K C=k^{\prime} C
$$

Rearranging and integration of Equation (11) yields the typical pseudo-first-order model as in Equations (12) and (13):

$$
\begin{aligned}
& C=C_{0} e^{-k^{\prime} t} \\
& \ln \left(\frac{C_{0}}{C}\right)=-k_{r} K t=-k^{\prime} t
\end{aligned}
$$

\subsection{Effect of $\mathrm{TiO}_{2}$ Loading}

The optimum concentration of $\mathrm{TiO}_{2} \mathrm{P}-25$ required for the decolourization of a $50 \mathrm{mg} \cdot \mathrm{L}^{-1} \mathrm{BB} 41$ solution was examined with the slurry method by varying the catalyst amount from $0.0-1.0 \mathrm{~g} \cdot \mathrm{L}^{-1}$. The results summarized in Table 1 indicate that the required photons, when the concentration of $\mathrm{TiO}_{2}$ increased to $0.4 \mathrm{~g} \cdot \mathrm{L}^{-1}$, were thoroughly absorbed. This shows that an increase in the amount of catalyst to the level consistent with the optimized level of light absorption increases the amount of 
Table 1. Effect of catalytic loading on photodegradation.

\begin{tabular}{ccc}
\hline S/No. & $\mathrm{TiO}_{2}\left(\mathrm{~g} \cdot \mathrm{L}^{-1}\right)$ & $K\left(\mathrm{Lmol}^{-1} \cdot \mathrm{min}^{-1}\right)$ \\
\hline 1 & 0.0 & - \\
2 & 0.2 & 0.018 \\
3 & 0.4 & 0.023 \\
4 & 0.6 & 0.014 \\
5 & 0.8 & 0.012 \\
6 & 1.0 & 0.011 \\
\hline
\end{tabular}

decolourization [38-40]. Thus, any further increase of the amount of the catalyst will have no effect on the photodegradation efficiency.

Concentration of $\mathrm{TiO}_{2}$ in the photocatalytic water treatment system affected the overall photocatalysis reaction rate in a true heterogeneous catalytic regime, where the amount of $\mathrm{TiO}_{2}$ is directly proportional to the overall photocatalytic reaction rate [41]. A linear dependency holds until certain extent when the reaction rate starts to aggravate and becomes independent of $\mathrm{TiO}_{2}$ concentration.

This is attributed to the geometry and working conditions of the photoreactor where the surface reaction is initiated upon light photon absorption [42]. When the amount of $\mathrm{TiO}_{2}$ increases above a saturation level (leading to a high turbidity state), the light photon absorption coefficient usually decreases radially. However, such a light attenuation over the radial distance could not be well correlated with the Beer-Lambert Law owing to the strong absorption and scattering of light photons by the $\mathrm{TiO}_{2}$ particles [43].

The excess $\mathrm{TiO}_{2}$ particles can create a light screening effect that reduces the surface area of $\mathrm{TiO}_{2}$ being exposed to light illumination and the photocatalytic efficiency. Therefore, any chosen photoreactor should be operated below the saturation level of $\mathrm{TiO}_{2}$ photocatalyst used to avoid excess catalyst and ensure efficient photons absorption. In this sense, both catalyst loading and light scattering effect can be considered as a function of optical path length in the reactor.

\subsection{Effect of Initial Dye Concentration}

To study the effect of dye concentration on the rate of decolourization, the BB41 concentrations were varied from $0,25,50,100 \& 150 \mathrm{mg} \cdot \mathrm{L}^{-1}$ while the other variables were kept constant.

Figure 3 shows the time dependence of unconverted fraction of dye $\left(C / C_{0}\right.$, where $C_{0}$ is the initial dye concentration and $\mathrm{C}$ is the dye concentration at time $t$ ) for the various initial concentrations $(0,25,50,100$ and 150 $\mathrm{mg} \cdot \mathrm{L}^{-1}$ ). Table 2 shows that the first-order-kinetic rela-

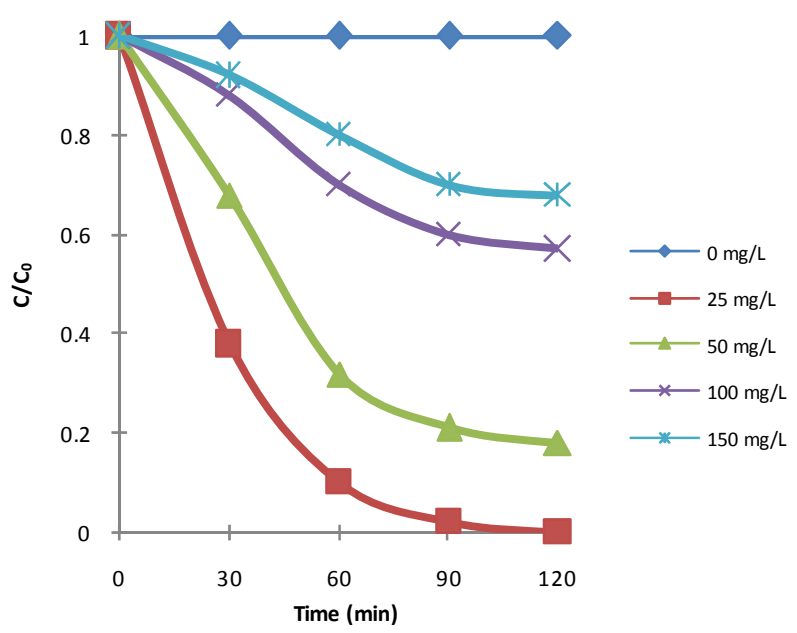

Figure 3. Photocatalytic decolourization of BB41 with different $\mathrm{TiO}_{2}$ loadings at different time intervals of irradiation.

Table 2. Effect of dye concentration on photodegradation of BB41.

\begin{tabular}{ccc}
\hline S/No. & Dye $\left(\mathrm{g} \cdot \mathrm{L}^{-1}\right)$ & $K\left(\mathrm{~L} \cdot \mathrm{mol}^{-1} \cdot \mathrm{min}^{-1}\right)$ \\
\hline 1 & 0.0 & ----- \\
2 & 25.0 & 0.010 \\
3 & 50.0 & 0.015 \\
4 & 100.0 & 0.005 \\
5 & 150.0 & 0.004 \\
\hline
\end{tabular}

tive to BB41 is operative. However, the apparent decolourization rate constant depends on the initial concentration of dye. As expected by increasing the concentration, the decolourization rate constant $(k)$ decreased.

The efficiency of dye degradation decreased with an increase in concentration of dye. The reason presumed is that in high dye concentrations, the active sites are covered with dye ions; subsequently, the production of OHC radicals on the surface of catalyst is reduced. Another possible reason for these results is the effect of UV screening of the own dye.

In high dye concentrations a major amount of UV is apt to be absorbed by dye molecules proportional to $\mathrm{OH}$ particles and this reduces the efficiency of the catalytic reaction due to the decline in $\mathrm{OHC}$ and $\mathrm{OH}_{2} \mathrm{C}$ concentrations [44]. Another possible reason is the intervention of the by-products formed during the degradation of mother dye molecules [45].

\subsection{Effect of pH}

In heterogeneous photocatalytic water system, $\mathrm{pH}$ is one of the most important operating parameters that affect the charge on the catalyst particles, size of catalyst aggre- 
gates and the positions of conductance and valence bands. Due to the nature of $\mathrm{TiO}_{2}$ catalyst used, any variation in the operating $\mathrm{pH}$ is known to affect the isoelectric point or the surface charge of the photocatalyst used.

Since dyes can to degrade at different $\mathrm{pHs}$ in coloured effluents, comparative experiments were performed at three $\mathrm{pH}$ values: one reasonably acidic, one reasonably basic and at the natural $\mathrm{pH} 5.5$ of BB41 (i.e. Natural pH of dye $5.5 \pm 2.5$ ). The studies were carried out at $\mathrm{pH}$ range 3.0 for the acidic solution and 8.0 for the basic solution.

The $\mathrm{pH}$ influences the characteristics of the photocatalyst surface charge, so $\mathrm{pH}$ of the solution is a significant parameter in performing the reaction on the surface of semiconductor particles. Point of zero charge (PZC) for $\mathrm{TiO}_{2}$ particles is $\mathrm{pH} \mathrm{PZC}=6.8$ [46]. The surface of $\mathrm{TiO}_{2}$ has a positive charge in acidic media $(\mathrm{pH}<6.8)$, so there is an electrostatic absorption between positive charge surfaces of $\mathrm{TiO}_{2}$ and the dye. As the $\mathrm{pH}$ of the system increases, the number of surfaces with negative charge increases. Thus, $\mathrm{H}_{2} \mathrm{SO}_{4}$ and $\mathrm{NaOH}$ were used for $\mathrm{pH}$ adjustment of dye solutions. The effect of $\mathrm{pH}$ on the degradation of dye is shown in Figure 4.

\subsection{Photocatalytic Mineralization of BB41}

The COD test was used to assess the degree of mineralization reached during the photocatalytic treatment. Usually, COD decreases with increase in irradiation time whereas the amount of inorganic ions increased with increase in irradiation time. The COD curve has an exponential or sigmoidal shape. The sigma-shaped curves indicate that they are related to the formation of relative tolerant by-products [44]. This pattern means that during the first step of the process where the solution is still coloured there is only a small decrease of the parameter measured (COD) due to the fact that dye molecules are decomposed to lower molecular weight compounds and the resulting intermediates still contribute to the COD of solution. After the decolourization of the solution, the

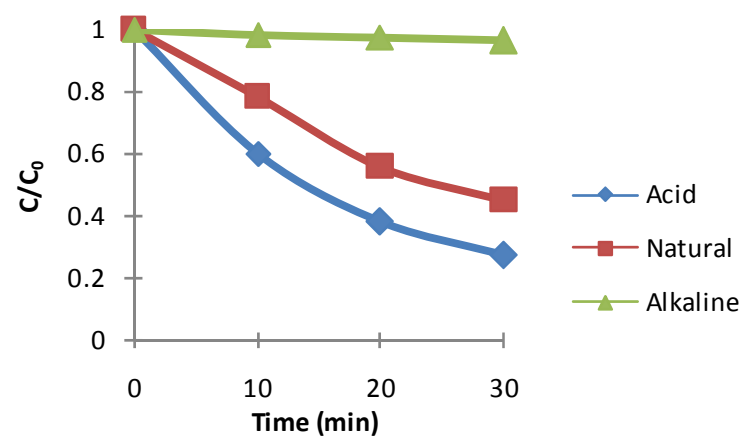

Figure 4. Effect of $\mathbf{p H}$ on the photocatalytic decolourization rate of BB41 $\left(C_{0}\right.$ : initial dye concentration, $C$ : dye concentration at time $t$ ).

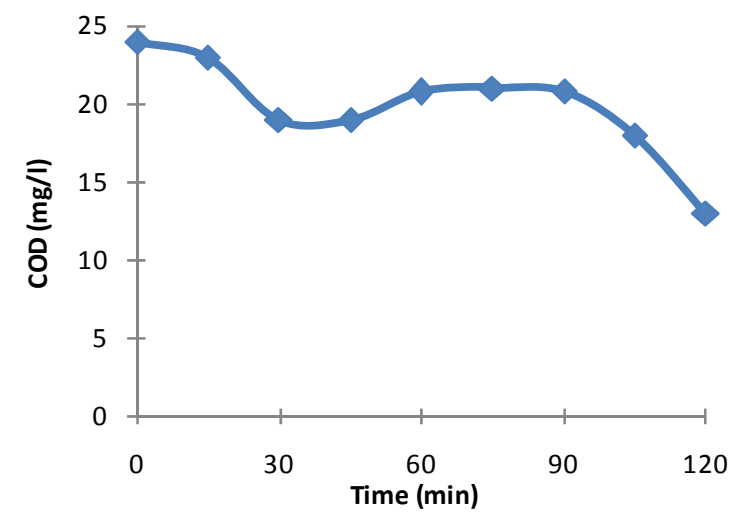

Figure 5. Decrease of COD with irradiation time.

COD decreased sharply, reaching a plateau that corresponds to the oxidation of most stable compounds, indicating that almost complete mineralization of intermediates has occurred. Figure 5 shows variation of COD with irradiation time.

\section{Conclusion}

The photocatalytic treatment of a textile dye, C. I. Basic Blue 41, from aqueous solution in a photocatalytic reactor was studied. The optimum value of the initial dye concentration was $50 \mathrm{~g} \cdot \mathrm{L}^{-1}$ and the operation medium was alkaline. The results of TOC decreased and UV-Vis indicated that photocatalytic process can be used for complete decolorization and mineralization of BB41.

\section{REFERENCES}

[1] S. Parsons, "Advanced Oxidation Processes for Water and Wastewater,” IWA Publishing, London, 2004.

[2] M. Zubair Alam, S. Ahmad, A. Malik and M. Ahmad, "Mutagenicity and Genotoxicity of Tannery Effluents Used for Irrigation at Kanpur, India,” Ecotoxicology and Environmental Safety, Vol. 73, No. 7, 2010, pp. 1620-1628. doi:10.1016/j.ecoenv.2010.07.009

[3] N. Nasuha, B. H. Hameed and A. T. M. Din, "Rejected Tea as a Potential Low-Cost Adsorbent for the Removal of Methylene Blue,” Journal of Hazardous Materials, Vol. 175, No. 1-3, 2010, pp. 126-132. doi:10.1016/j.jhazmat.2009.09.138

[4] M. A. Rauf, S. M. Qadri, S. Ashraf and K. M. Al-Mansoori, "Adsorption Studies of Toluidine Blue from Aqueous Solutions onto Gypsum,” Chemical Engineering Journal, Vol. 150, No. 1, 2009, pp. 90-95. doi:10.1016/j.cej.2008.12.008

[5] A. L. Ahmad and S. W. Puasa, "Reactive Dyes Decolourization from an Aqueous Solution by Combined Coagulation/Micellar-Enhanced Ultrafiltration Process,” Chemical Engineering Journal, Vol. 132, No. 1-3, 2007, pp. 257265. doi:10.1016/j.cej.2007.01.005

[6] M. Riera-Torres, C. Gutiérrez-Bouzán and M. Crespi, “Combination of Coagulation-Flocculation and Nanofiltration 
Techniques for Dye Removal and Water Reuse in Textile Effluents,” Desalination, Vol. 252, No. 1-3, 2010, pp. 5359. doi:10.1016/j.desal.2009.11.002

[7] K. Shakir, A. F. Elkafrawy, H. F. Ghoneimy, S. G. Elrab Beheir and M. Refaat, "Removal of Rhodamine B (A Basic Dye) and Thoron (an Acidic Dye) from Dilute Aqueous Solutions and Wastewater Simulants by Ion Flotation," Water Research, Vol. 44, No. 5, 2010, pp. 1449-1461. doi:10.1016/j.watres.2009.10.029

[8] S. Zodi, O. Potier, F. Lapicque and J.-P. Leclerc, "Treatment of the Industrial Wastewaters by Electrocoagulation: Optimization of Coupled Electrochemical and Sedimentation Processes,” Desalination, Vol. 261, No. 1-2, 2010, pp. 186-190. doi:10.1016/j.desal.2010.04.024

[9] M. A. Rauf and S. S. Ashraf, "Application of Advanced Oxidation Processes (AOP) to Dye Degradation-An Overview," In: A. R. Lang, Ed., Dyes and Pigments: New Research, Nova Science Publishers, Inc., Hauppauge, 2009.

[10] M. R. Hoffmann, S. T. Martin, W. Choi and D. Bahnemann, "Environmental Applications of Semiconductor Photocatalysis," Chemical Review, Vol. 95, No. 1, 1995, pp. 69-96. doi:10.1021/cr00033a004

[11] M. I. Litter, "Heterogeneous Photocatalysis Transition Metal Ions in Photocatalytic Systems," Applied Catalysis B: Environmental, Vol. 23, No. 2-3, 1999, pp. 89-114. doi:10.1016/S0926-3373(99)00069-7

[12] M. C. Yeber, J. Rodriguez, J. Freer, J. Baeza, N. Duran and H. D. Mansilla, "Advanced Oxidation of a Pulp Mill Bleaching Wastewater,” Chemosphere, Vol. 39, No. 10, 1999, pp. 1679-1683. doi:10.1016/S0045-6535(99)00068-5

[13] Y. Wang, "Solar Photocatalytic Degradation of Eight Commercial Dyes in $\mathrm{TiO}_{2}$ Suspension," Water Research, Vol. 34, No. 3, 2000, pp. 990-994. doi:10.1016/S0043-1354(99)00210-9

[14] M. Vautier, C. Guillard and J. M. Herrmann, "Photocatalytic Degradation of Dyes in Water: Case Study of Indigo and of Indigo Carmine,” Journal of Catalysis, Vol. 201, No. 1, 2001, pp. 46-59. doi:10.1006/jcat.2001.3232

[15] T. M. Elmorsi, Y. M. Riyad, Z. H. Mohamed and H. M. H. Abd El Bary, "Decolourization of Mordant Red 73 Azo Dye in Water Using $\mathrm{H}_{2} \mathrm{O}_{2} / \mathrm{UV}$ and Photo-Fenton Treatment,” Journal of Hazardous Materials, Vol. 174, No. 1-3, 2010, pp. 352-358. doi:10.1016/j.jhazmat.2009.09.057

[16] F. H. AlHamedi, M. A. Rauf and S. S. Ashraf, "Degradation Studies of Rhodamine B in the Presence of $\mathrm{UV} / \mathrm{H}_{2} \mathrm{O}_{2}$," Desalination, Vol. 239, No. 1-3, 2009, pp. 159-166. doi:10.1016/j.desal.2008.03.016

[17] A. Masarwa, S. Rachmilovich-Calis, N. Meyerstein and D. Meyerstein, "Oxidation of Organic Substrates in Aerated Aqueous Solutions by the Fenton Reagent," Coordination Chemistry Reviews, Vol. 249, No. 17-18, 2005, pp. 1937-1943. doi:10.1016/j.ccr.2005.01.003

[18] C. Bouasla, M. E.-H. Samar and F. Ismail, "Degradation of Methyl Violet 6B Dye by the Fenton Process," Desalination, Vol. 254, No. 1-3, 2010, pp. 35-41. doi:10.1016/j.desal.2009.12.017
[19] J. M. Monteagudo, A. Durán, I. S. Martín and M. Aguirre, "Catalytic Degradation of Orange II in a Ferrioxalate-Assisted Photo-Fenton Process Using a Combined UV-A/CSolar Pilot-Plant System," Applied Catalysis B: Environmental, Vol. 95, No. 1-2, 2010, pp. 120-129. doi:10.1016/j.apcatb.2009.12.018

[20] A. K. Abdessalem, N. Bellakhal, N. Oturan, M. Dachraoui and M. A. Oturan, "Treatment of a Mixture of Three Pesticides by Photo- and Electro-Fenton Processes,” Desalination, Vol. 250, No. 1, 2010, pp. 450-455. doi:10.1016/j.desal.2009.09.072

[21] A. R. Tehrani-Bagha, N. M. Mahmoodi and F. M. Menger, "Degradation of a Persistent Organic Dye from Coloured Textile Wastewater by Ozonation,” Desalination, Vol. 260, No. 1-3, 2010, pp. 34-38. doi:10.1016/j.desal.2010.05.004

[22] S. Merouani, O. Hamdaoui, F. Saoudi and M. Chiha, "Sonochemical Degradation of Rhodamine B in Aqueous Phase: Effects of Additives," Chemical Engineering Journal, Vol. 158, No. 3, 2010, pp. 550-557. doi:10.1016/j.cej.2010.01.048

[23] X. Wang, Z. Yao, J. Wang, W. Guo and G. Li, “Degradation of Reactive Brilliant Red in Aqueous Solution by Ultrasonic Cavitation,” Ultrasonics Sonochemistry, Vol. 15, No. 1, 2008, pp. 43-48. doi:10.1016/j.cej.2010.01.048

[24] M. A. Rauf, M. A. Meetani, A. Khaleel and A. Ahmed, "Photocatalytic Degradation of Methylene Blue Using a Mixed Catalyst and Product Analysis by LC/MS," Chemical Engineering Journal, Vol. 157, No. 2-3, 2010, pp. 373-378. doi:10.1016/j.cej.2009.11.017

[25] R. Xu, J. Li, J. Wang, X. Wang, B. Liu, B. Wang, X. Luan and X. Zhang, "Photocatalytic Degradation of Organic Dyes under Solar Light Irradiation Combined with $\mathrm{Er}^{3+}$ : $\mathrm{YAlO}_{3} / \mathrm{Fe}$ - and Co-Doped $\mathrm{TiO}_{2}$ Coated Composites," Solar Energy Materials and Solar Cells, Vol. 94, No. 6, 2010, pp. 1157-1165. doi:10.1016/j.solmat.2010.03.003

[26] L. Ayed, K. Chaieb, A. Cheref and A. Bakhrouf, "Biodegradation and Decolourization of Triphenylmethane Dyes by Staphylococcus Epidermidis,” Desalination, Vol. 260, No. 1-3, 2010, pp. 137-146. doi:10.1016/j.desal.2010.04.052

[27] Ö. ÇInar, S. Yasar, M. Kertmen, K. Demiröz, N. Ö. Yigit and M. Kitis, "Effect of Cycle Time on Biodegradation of Azo Dye in Sequencing Batch Reactor,” Process Safety and Environmental Protection, Vol. 86, No. 6, 2008, pp. 455-460. doi:10.1016/j.psep.2008.03.001

[28] A. Vahdat, S. H. Bahrami, M. Arami and A. Motahari, "Decomposition and Decolouration of a Direct Dye by Electron Beam Radiation," Radiation Physics and Chemistry, Vol. 79, No. 1, 2010, pp. 33-35. doi:10.1016/j.radphyschem.2009.08.012

[29] K. A. Mohamed, A. A. Basfar and A. A. Al-Shahrani, "Gamma-Ray Induced Degradation of Diazinon and Atrazine in Natural Groundwaters,” Journal of Hazardous Materials, Vol. 166, No. 2-3, 2009, pp. 810-814. doi:10.1016/j.jhazmat.2008.11.081

[30] L. Andronic, A. Enesca, C. Vladuta and A. Duta, "Photocatalytic Activity of Cadmium Doped $\mathrm{TiO}_{2}$ Films for Photocatalytic Degradation of Dyes," Chemical Engineering Journal, Vol. 152, No. 1, 2009, pp. 64-71. 
doi:10.1016/j.cej.2009.03.031

[31] Z. M. El-Bahy, A. A. Ismail and R. M. Mohamed, “Enhancement of Titania by Doping Rare Earth for Photodegradation of Organic Dye (Direct Blue)," Journal of Hazardous Materials, Vol. 166, No. 1, 2009, pp. 138-143. doi:10.1016/j.jhazmat.2008.11.022

[32] U. Diebold, "The Surface Science of Titanium Dioxide," Surface Science Reports, Vol. 48, No. 5-9, 2003, pp. 53229. doi:10.1016/S0167-5729(02)00100-0

[33] Y. B. Xie and X. Z. Li, "Interactive Oxidation of Photoelectrocatalysis and Electro-Fenton for Azo Dye Degradation Using $\mathrm{TiO}_{2}$-Ti Mesh and Reticulated Vitreous Carbon Electrodes," Materials Chemistry and Physics, Vol. 95, No. 1, 2006, pp. 39-50. doi:10.1016/j.matchemphys.2005.05.048

[34] A. Giwa, P. O. Nkeonye, K. A. Bello, E. G. Kolawole and A. M. F. Oliveira, "Campos, Solar Photocatalytic Degradation of Reactive Yellow 81 and Reactive Violet 1 in Aqueous Solution Containing Semiconductor Oxides," International Journal of Applied Science and Technology, Vol. 2. No. 4, 2012, pp. 90-105.

[35] M. N. Chong, B. Jin, H. Y. Zhu, C. W. K. Chow and C. Saint, "Application of H-Titanate Nanofibers for Degradation of Congo Red in an Annular Slurry Photoreactor," Chemical Engineering Journal, Vol. 150, No. 1, 2009, pp. 49-54. doi:10.1016/j.cej.2008.12.002

[36] S. Malato, P. Fernandez-Ibanez, M. I. Maldonado, J. Blanco and W. Gernjak, "Decontamination and Disinfection of Water by Solar Photocatalysis: Recent Overview and Trends," Catalysis Today, Vol. 147, No. 1, 2009, pp. 1-59. doi:10.1016/j.cattod.2009.06.018

[37] D. Monllor-Satoca, R. Gomez, M. Gonzalez-Hidalgo and P. Salvador, “The 'Direct-Indirect' Model: An Alternative Kinetic Approach in Heterogeneous Photocatalysis Based on the Degree of Interaction of Dissolved Pollutant Species with the Semiconductor Surface," Catalysis Today, Vol. 129, No. 1-2, 2007, pp. 247-255. doi:10.1016/j.cattod.2007.08.002

[38] A. F. Caliman, C. Cojocarru, A. Antoniadis and L. Poulios, "Optimized Photocatalytic Degradation of Alcian Blue 8 GX in the Presence of $\mathrm{TiO}_{2}$ Suspensions," Journal of Hazardous Materials, Vol. 144, No. 1-2, 2007, pp. 265-

\section{3. doi:10.1016/j.jhazmat.2006.10.019}

[39] A. B. Prevot, M. Vincenti, A. Bianciotto and E. Pramauro, "Photocatalytic and Photolytic Transformation of Chloramben in Aqueous Solutions," Applied Catalysis B: Environmental, Vol. 22, No. 6, 1999, pp. 149-158. doi:10.1016/S0926-3373(99)00046-6

[40] J. P. Percherancier, R. Chapelon and B. Pouyet, "Semiconductor-Sensitized Photodegradation of Pesticides in Water: The Case of Carbetamide,” Journal of Photochemistry and Photobiology A: Chemistry, Vol. 87, No. 3, 1995, pp. 261-266. doi:10.1016/1010-6030(94)03993-5

[41] U. I. Gaya and A. H. Abdullah, "Heterogeneous Photocatalytic Degradation of Organic Contaminants over Titanium Dioxide: A Review of Fundamentals, Progress and Problems," Journal of Photochemistry and Photobiology C: Photochemistry Reviews, Vol. 9, No. 1, 2008, pp. 1-12. doi:10.1016/j.jphotochemrev.2007.12.003

[42] D. Bamba, P. Atheba, D. Robert, A. Trokourey and B. Dongui, "Photocatalytic Degradation of the Diuron Pesticide,” Environmental Chemistry Letters, Vol. 6, No. 3, 2008, pp. 163-167. doi:10.1007/s10311-007-0118-X

[43] C. C. Chen, C. S. Lu, Y. C. Chung and J. L. Jan, "UV Light Induced Photodegradation of Malachite Green on $\mathrm{TiO}_{2}$ Nanoparticles," Journal of Hazardous Materials, Vol. 141, No. 3, 2007, pp. 520-528. doi:10.1016/j.jhazmat.2006.07.011

[44] I. K. Konstantinou and T. A. Albanis, " $\mathrm{TiO}_{2}$-Assisted Photocatalytic Degradation of Azo Dyes in Aqueous Solution: Kinetic and Mechanistic Investigations: A Review," Applied Catalysis B: Environmental, Vol. 49, No. 1, 2004, pp. 1-14. doi:10.1016/j.apcatb.2003.11.010

[45] A. Giwa, P. O. Nkeonye, K. A. Bello and E. G. Kolawole, "Solar Photocatalytic Degradation of Acid Blue 29," Journal of the Chemical Society of Nigeria, Vol. 36. No. 1, 2011, pp. 82-89.

[46] F. Zhang, J. Zhaoa, T. Shen, H. Hidaka, E. Pelizzetti and N. Serpone, " $\mathrm{TiO}_{2}$-Assisted Photodegradation of Dye Pollutants II. Adsorption and Degradation Kinetics of Eosin in $\mathrm{TiO}_{2}$ Dispersions under Visible Light Irradiation," $A p$ plied Catalysis B: Environmental, Vol. 15, No. 1-2, 1998, pp. 147-156. doi:10.1016/S0926-3373(97)00043-X 